\author{
James David McCoy, D.D.S., Editor \\ Los ANGELES, CALIF.
}

\title{
SOME OBSERVATIONS CONCERNING THE REQUIREMENTS OF THE RADIOGRAPHER AND DESCRIPTIVE TERMINOLOGY
}

\author{
By James David McCoy, D.D.S., Los Angeles, Calif. \\ Professor of Orthodontia and Radiography, College of Dentistry, University of \\ Southern California
}

$\mathrm{W}^{\mathrm{H}}$

HEN William Conrad Roentgen announced his discovery to the world, he called it the $x$-ray, but the civilized world has for the most part seen fit to designate it the roentgen ray in honor of the discoverer. Roentgenology is, therefore, defined as "the study and practice of the roentgen ray, as it applies to medicine and surgery."

For purposes of study, roentgenology may be divided into two distinct fields, depending upon the purpose for which the roentgen ray is to be utilized. In the first, which is the one enlisting the interest of dentists, it is used for the production of shadow pictures or radiograms. In other words, it embraces what is commonly called the field of radiography, or roentgenography.

The other branch mentioned, includes the use of the roentgen ray for therapeutic purposes, and is known as radiotherapy, or roentgenotherapy. With this field, the dentist is happily not directly concerned, and, therefore, his responsibilities are not as great as the medical roentgenologist.

Of the various collateral sciences of medicine, there is perhaps none which has developed more rapidly, or which has assumed a more important bearing in many branches of practice than has the science of roentgenology. With the increased appreciation of its value and its wide adoption, it has been developed through a comparatively short period of evolution, until now it can be regarded, broadly speaking, in the light of an exact science.

In spite of this fact, there is still apparent a great degree of misconception as to the responsibilities of one who is to actively engage in this work.

To the uninitatcd, this ficld of labor often presents alluring possibilities, and they are all too apt to rush in without adequate preparation. To such, the reward of bitter disappointment must eventually come, when they become mired in the mud of their own poor judgment, and lack of technical knowledge. 
To avoid such an end, or perhaps what is almost as ignominions, the acquiring of "a partial knowledge" of the subject, which at best can only carry one-half way upon the journey of success-the student should first come to a realization that the practice of roentgenology or any of its branches requires more than a mere training in the mechanics of the x-ray laboratory.

Undoubtedly, many a man has, in the contemplation of x-ray apparatus for his office, given serious thought to the type of the equipment which he wished to install, and has assumed that with a modern laboratory, he would be in a position to render the best of service. Such a misguided individual all too soon learns that a zery large part of the battle lis within himself, and if his own knowledge is deficient, the finest equipment in the world will not make him a roentgenologist.

It is important, therefore, that those who contemplate any indulgence in the field of radiography should not underestimate the task which confronts them.

In addition to becoming familiar with the electrophysics of $x$-ray laboratory equipment, its practical application in their chosen field, the dangers which sur. round it if improperly used, one should realize that the real practice of radiography begins when the $\mathrm{x}$-ray picture, or radiogram, has been produced. It is quite impossible for stch an image to be of value, unless the radiographer is thoroughly familiar with the anatomy, physiology, and pathology of the field under examination, and even these qualifications are not adequate unles backed up by practical clinical experience.

For those who can qualify, there is a real field and a rare opportunity, and it will be found that every man who engages in this work will receive just that amount of recognition and respect from his colleagues to which his abilities entitle him.

One of the first things which the beginner should do is to become familiar with the terminology of this subject, and cultivate the habit of using terms correctly. Instead of using the term $x$-ray picture, such an image should always be spoken of as a radiogram, or as a roentgenogram.

The physician or dentist maintaining an $\mathrm{x}$-ray laboratory, should not he called an $x$-ray specialist, but should be spoken of as a medical or a dental roentgenologist.

Not infrequently, we hear physicians or dentists speaking of a dental radiogram as a dental $x$-ray. Such an expression only exposes their crudity of thought, and certainly expresses nothing else.

It is thought by some terminologists that in addition to always speaking of the $x$-ray as the roentgen ray, in honor of the man who discovered it, we should include the name Roentgen in every descriptive word connected with the work. To such, the term radiograph (verb) and radiogram (noun) will doubtless appear improper, but I feel justified in continuing their use, as these words are thoroughly descriptive and less cumbersome than roentgenograph and roentgenogram. For the same reason, the term radiography is preferred rather than roentgenography to designate the art of making radiograms.

Briefly summarized, the following roentgen terminology will be found to be quite adequate: 
Roentgen ray, or

X-ray :

Roentgenology, or

Radiology :*

Roentgenologist, or Radiologist :*

Roentgenogram, or Radiogram :

Roentgenograph, or Radiograph :

Roentgenography, or Radiography:

Roentgenotherapy, or Radiotherapy :*

Roentgen dermatitis, or $\mathrm{X}$-ray dermatitis:
A phenomenon in physics discovered by William Conrad Roentgen.

The study and practice of the roentgen ray as applied to medicine and surgery.

One skilled in roentgenology.

The shadow picture produced by the $\mathrm{x}$-ray upon the photographic cmulsion.

(Verb.) To make a roentgenngram, or radiogram.

The art of making roentgenograms, or radiograms.

Treatment by the application of the roentgen ray.

Skin reaction due to too strong or too often repeated application of the roentgen ray.

Roentgenographic examination, or The examination and study of the shadRadiographic examination: ow pictures produced by the $\mathrm{x}$-ray upon the photographic emulsion.

Roentgen diagnosis, or

$\mathrm{X}$-ray diagnosis:

Diagnosis by aid of the roentgen ray.

Pathoroentgenography, or Pathoradiography:

Roentgenize :

To apply the roentgen ray

Roentgenization :

The application of the roentgen ray.

Roentgenism :

Some writers add other descriptive terms to the foregoing list, but I feel that a terminology should be just as brief as is consistent with adequate description; hence, several terms appearing in current literature on different phases of roentgenology have been omitted.

* The term is rather confusing, as it could also refer to the practice and therapy of radium or other radiotherapeutic agents. 